\title{
Prevention of Water Accidents
}

\author{
-A Half Century Reviewed-
}

BY RICHARD L. BROWN, M.S.

$\mathrm{T}$

HE DROWNING RATE per 100,000 population in the United States has been cut in half in the past 40 years, in spite of the fact that the number of people using aquatic facilities has multiplied many times.

This remarkable accomplishment in reducing aquatic accidents and spreading the message of water safety can be attributed to many factors-the primary one of which is doubtless the efforts made by the many organizations concerned with health, safety, and recreation.

At the turn of the century, little was being done to teach people how to swim, or to protect them in any way when they went swimming. Few pools existed. The Young Men's Christian Association was one of the few national organizations that had made any attempt to encourage swimming skills among their membership. With their interest in the field of physical education it was natural that they should be among the first to include swimming pools in their facilities. The first YMCA pool, 14 by 45 feet, built in 1885 in Brooklyn, was called a swimming bath. Detroit followed in 1886 with a natatorium that included a pool 16 by 3 ? feet. By 1909 there were 293 YMCA swimming pools

Mr. Brown is the assistant director of the Water Safety Service of the American National Red Cross and secretary-treasurer of the Conference for $\mathrm{Na}$ tional Cooperation in Aquatics. in the United States. Today there are more than 600 .

Meanwhile, in Providence, R. I., a waterfront reporter, the late Commodore Wilbert E. Longfellow, was becoming highly interested in the drowning problem. While covering the east side of the Providence River and upper Narragansett Bay he became concerned over the high frequency of the preventable drowningscaused mainly because of lack of swimming and lifesaving knowledge and adequate supervision.

"Bathing beaches in 1900 were a far cry from the modern swimming resorts and pools of today," he recounted. "Women were swathed from chin to toe in clumsy suits that made swimming almost impossible. Beaches lacked rescue equipment and life guards frequently doubled as waiters. Rescue methods were mostly of the 'bust 'em in the jaw and roll 'em over the barrel' type."

\section{Early Lifesaving Activities}

To help correct the situation young Longfellow volunteered his spare time to the United States Volunteer Life Saving Corps, one of the few organizations concerned with the problem and active in only a few eastern cities. In 1909 he received the title "commodore" and appointment as State superintendent of the corps in Rhode Island. Undaunted by a spinal disease which confined him to bed and threatened his life in 1907, the commodore carried on his life- 
saving work by means of correspondence. During convalescence he toured the waterfront giving lectures, and, with the aid of an assistant, demonstrations. In 1909, he became commodore in chief and general superintendent of the corps in New York.

Now recognized as a national authority on water safety, Longfellow was asked to prepare material on lifesaving for the Boy Scout Handbook, published in 1911. The Boy Scouts, with their establishment in 1910, had specified swimming and water safety as part of their program.

Encouraged by the success of lifesaving efforts in Rhode Island and New York, Longfellow urged nationwide expansion of the VLSC. When the governing body failed to endorse this proposal he began to seek elsewhere for assistance.

Commodore Longfellow had met Major Charles Lynch who had written the first-aid material for the Boy Scout Handbook and was in charge of the first-aid department of the American National Red Cross. Longfellow expressed the idea that lifesaving and water safety should go hand in hand with the Red Cross program of first aid.

Meanwhile, officials of the YMCA and the Boy Scouts of America also expressed to Major Lynch the idea that Red Cross might assume some responsibility in lifesaving and water safety. As a result, a committee was formed to outline recommendations for such a project. The committee included Longfellow, James W. West of the Boy Scouts, and Dr. George J. Fisher and William H. Ball of the YMCA. On May 14, 1913, Mr. Ball and Major Lynch met at a YMCA in New York and outlined proposed objectives of the lifesaving corps of the American Red Cross. Both agreed that Commodore Longfellow should provide the leadership for this project. In December the governing body of the Red Cross approved the project and on February 1, 1914, Commodore Longfellow began work with the Red Cross-a work he was to continue until shortly before his death in 1947.

Longfellow's first assignment was in Baltimore, Md., where he organized the first Volunteer Life Saving Corps at the YMCA. The second corps, also in Baltimore, was composed primarily of Boy Scout leaders. From Balti- more the commodore proceeded to other States, taking the message of water safety and forming volunteer lifesaving corps. By the end of 1916 nearly all parts of the Nation had been visited by the representative. Everywhere he enlisted the cooperation of many groups, YMCA's, Scouts, police, and other civic groups, and the military.

World War I gave impetus to water safety training for members of the armed forces, and in many cases proved the value of such training. The YMCA reports many a young man home safely after his ship had sunk made the statement: "My life was saved because I learned to swim in the YMCA pool." Very early in his work the commodore had given demonstrations for navy personnel and civilian employees. With the entrance of this country into the war, he worked extensively in army camps, at naval stations, and with the Coast Guard and Marine Corps giving demonstrations and teaching lifesaving and water safety methods to thousands. In fact, it was here that what later was to become known as survival swimming first got its start-with the commodore's demonstrations of "shirt tail" lifesaving.

\section{Swimming for Women}

During this early period opportunity for swimming for women and girls was limited, primarily because of lack of facilities except in the summertime.

However, the Young Women's Christian Association was getting its aquatic programs started with new building programs including pool facilities. The first YWCA pool had been built in 1905 and from the beginning swimming had always been considered an important part of the organization's physical education program. By 1954 there were 132 pools.

In 1912 the Girl Scouts got under way and from the beginning expressed interest in aquatic activities. The first handbook, published in 1917 , included advice on supervision and training for swimming and boating.

Primarily through the efforts of the commodore, who did not share the opinion of some that women should not be accepted as lifesavers on an equal basis with men, some two or three thousand women were qualified as lifesavers by 

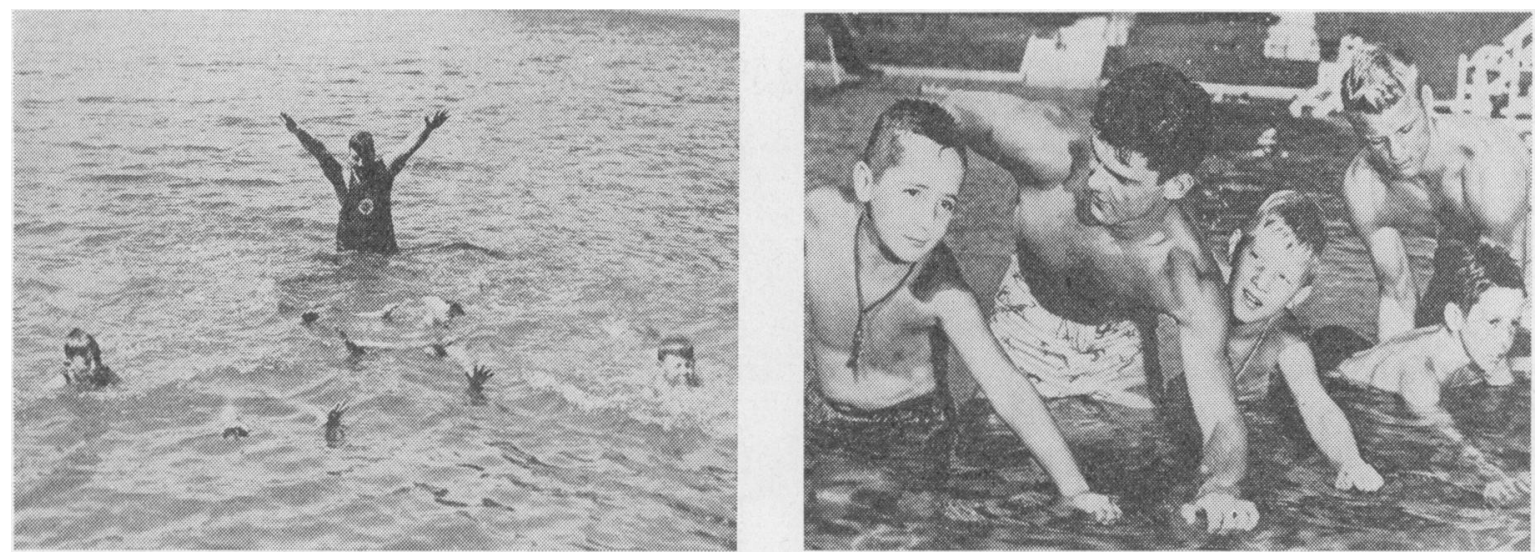

Left: A swimming lesson in the early days of the water safety program. Right: A trained instructor teaches youngsters to swim in one of the many modern pools constructed in the past $\mathbf{4 0}$ years.

1920. In that year the Red Cross recognized women as members of lifesaving corps and by 1921 women were accepted as members and examiners on the same basis as men.

Following the war, interest in swimming increased steadily-as it has to the present day. Many new pools were being added, not only by the YMCA and the YWCA, but also by boys' clubs, Jewish community centers, service clubs, schools and colleges, recreation departments, and other community groups. At the same time, greater awareness of the health and safety problems was being expressed by local communities and gradually natural swimming places were improved for recreational purposes. As transportation methods improved, accessibility of swimming spots naturally resulted in greater interest in aquatics for recreation.

While the popularity of swimming climbed steadily in the ensuing years - the drowning rate steadily declined. According to the National Safety Council publication, Accident Facts, 1953 edition, the drowning rate average in $1913-17$ was 8.8 per 100,000 population. By 1927 the average had dropped to 6.4 and by 1952 it stood at 4.4 .

\section{Widening the Program}

While initially the efforts of the Red Cross, and to some extent that of other organizations, had been primarily in lifesaving, it soon became apparent that a more basic need existed-to teach more people how to swim so aquatic accidents could be prevented. As more and more recreation areas opened up, a new need became apparent-the need to reach more people with training and information on safety in operation of small craft. Whereas such activity had been included for many years in private and organizational camping, the popularity of small craft took a big jump following World War II. As a result, many organizations increased their educational efforts in this field.

Today there are countless groups, national, State, and local, concerned with the problem of death by drowning and making an effort to plan safer, healthier aquatic recreation for Americans. The following is a brief summary of the objectives and programs of the major national organizations concerned with a direct program of education in water safety. Most of these organizations publish educational materials-texts, pamphlets, posters, and the like. Details of materials available can be obtained by writing to the specific organizations.

American National Red C'ross. Objectives: To reduce drownings by teaching people how to be safe in, on, or near the water, to perform rescue, and to give assistance in case of accidents. Operates through local chapters in cooperation with other groups. Does not operate facilities. Offers graduated courses in swimming, from beginner through advanced, open to persons of all ages; junior lifesaving for boys and girls 12 to 15 years of age; senior lifesaving for men and women 16 years of age or older; survival swimming for persons 16 years of age or older; basic courses in boating, canoeing and sailing, open to persons of all ages. Some chap- 
ters also participate in cooperative programs of swimming for the handicapped. Courses conducted by trained volunteer instructors. Leadership training conducted by professional field staff and at 10-day aquatic and small craft schools annually in June and August throughout the Nation.

Boy Scouts of America. Objectives: To aid every Scout to be at home in and on the water; to instruct him in self-preservation and to aid others in and on the water; to give Scouts fun in and on the water. Operates through the Scout units (Cub Scout packs, Boy Scout troops, and Explorer units). Cub Scouts are urged to learn to swim progressively with an adult person who can help supervise them. Boy Scouts and Explorers learn through an advancement plan including a 50-yard swim for first-class rank and merit badges for swimming, lifesaving, rowing, and canoeing. Opportunity to become a Scout lifeguard for proficiency in basic aquatic skills and proved ability to use them to aid others. Sea Explorer program includes sailing, navigation, seamanship. Primary facilities are at Scout camps and, in addition, on year-round basis using public and private community pools. Leadership training given through professional staff and at aquatic schools conducted throughout the Nation each June.

Boys Clubs of America. Objectives : To teach boys to swim and become proficient in water skill; to teach lifesaving techniques and skill in handling water craft. Operates through club pools, at summer camps and through use of community resources. Most clubs have aquatic programs. Swimming program based on Boys Clubs of America aquatic tests; lifesaving based on Red Cross junior and senior lifesaving courses. Some clubs offer small craft handling. Utilize aquatic leadership training offered by Red Cross and other groups plus own professional staff.

Girl Sconts of the U.S.A. Objectives: To teach girls to swim and to handle small craft so they are able to take care of themselves in or on the water; to help girls be aware of their responsibility for their own safety and that of others. Operates through Girl Scout troops. Proficiency badge program for Intermediate Scouts includes swimming, lifesaving, boating, and canoeing. Senior Girl Scout troops especially interested in aquatic activities may carry out mariner program, including logical progression for various activities. Opportunity for aquatics available at Girl Scout camps operated throughout the Nation during summer months. Year-round activities utilize private and public schools. Utilizes leadership training offered by Red Cross, plus own professional staff.

National Jewish.Welfare Board. Objectives: To offer swimming as a part of the health and physical education program. Health and physical education manual indicates "Swimming is one of three essential things which a father is duty bound to teach his children ... physiologically, swimming is one of the best forms of exercise." Operates through Jewish community centers and YMHA's having swimming pools, plus day or country camps where there are swimming facilities. Centers without pools utilize community resources in public and private pools. Program includes instruction, recreation and special events. Utilizes Red Cross leadership training and courses.

Young Men's Christian Association. Objectives: Learning to swim for recreation; safety including personal safety as well as attention to fellow swimmers; being useful to others; health and physical fitness. Operates through own pools on year round basis and summer camps. Program includes swimming, lifesaving and water safety, and wide range of water sports, games, and recreational activities. Nearly every YMCA has a professionally trained and qualified specialist in swimming, safety, and lifesaving, prepared to instruct. Provides instruction for personnel of other groups. Provides qualified leadership through professional field agents plus a national aquatic conference held every 5 years. Carries on extensive aquatic research at two YMCA colleges-Springfield and George Williams.

Young Women's Christian Association. Objectives: As a part of health education, to develop a program that will help produce for its members, including staff and volunteers, through individual, group, and community programs, sound health practices, recreational skills and personalities capable of enjoying the creative life. Water safety is a specific objective. Operates through own pools and camps 

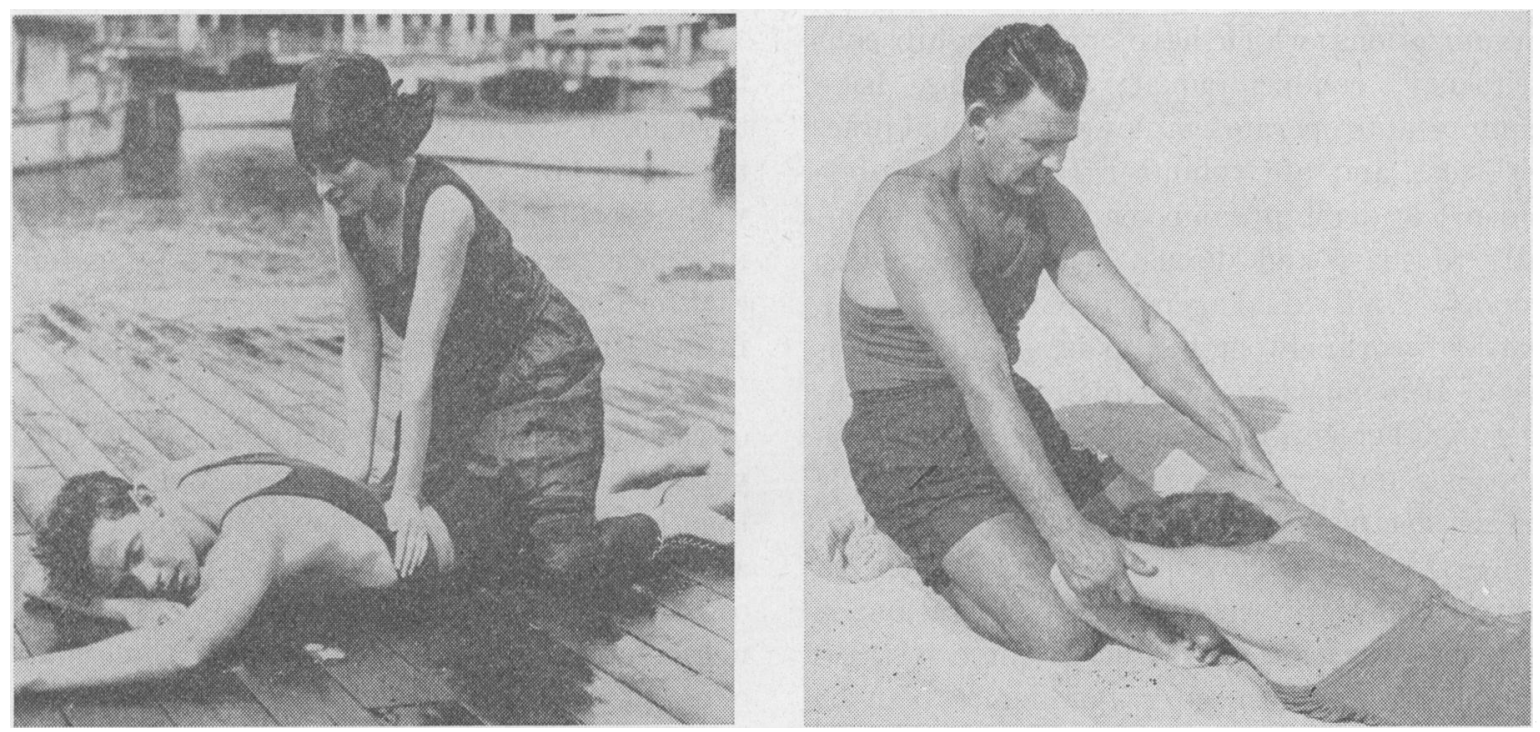

The Schaefer prone pressure method of artificial respiration, left, was developed in $1903 . \quad$ In 1951 if was superseded by the back pressure-arm lift method, right.

and also pool facilities rented from other organizations. Program includes instruction in swimming, diving, lifesaving, health education, rehabilitation and corrective physical education on a limited scale; water games and contests; water pageantry; synchronized swimming, social recreation, and some small craft. Instructors must have background of good experience in teaching swimming. Most are full-time members of health education staff with degrees in physical education. Also utilize leadership training and courses of other groups.

While each of the above organizations carries out a specific program of water safety education, there are countless other groups, national, regional, and local, which have contributed a great deal toward promotion and public education in water safety practices. It would be impossible to compile a complete list-but it would include many youth groups, civic clubs, governmental units, service clubs, schools and colleges, publicity and advertising media, industries, recreation and safety groups.

Pools operated by municipal recreation and park departments are utilized not only for learn-to-swim programs but for training of lifeguards, instructors, and others. According to the National Recreation Association, there are more than 2,000 municipal pools, most of which offer facilities for education in swimming and water safety. In addition, they provide an op- portunity for many persons to swim under supervision of trained lifeguards.

\section{Safety a Common Objective}

In many communities the programs of water safety are interrelated-all united in a common objective- to teach more persons to swim and to practice safety while in, on, or about the water.

To carry this idea of cooperation even further, the Conference for National Cooperation in Aquatics is working nationally and locally to extend aquatic programs. The organization includes not only those already listed but also the following groups having a direct interest in aquatics: American Association for Health, Physical Education, and Recreation; American Camping Association; American Recreation Society; Athletic Institute; Committee on Relationship with the Armed Forces; Amateur Athletic Union of the United States; National Collegiate Athletic Association; National Federation of State High School Athletic Associations; National Recreation Association; National Safety Council; National Social Welfare Assembly ; United States Office of Education; and Women's National Aquatic Forum.

The purpose of the conference, as outlined in a report of the third annual meeting last October, is to provide a setting in which national 
organizations, which have a membership constituency, conduct aquatic programs, have equipment to operate, employ professional practitioners, and use volunteer (and semiprofessional) leadership, can come together occasionally to share and discuss common problems, report on individual agency programs, and plan ways of working together on agreed-upon projects. It is hoped that this planning and working together will bring understanding between agencies and serve a greater number of people more effectively. At the recent meeting main subjects of discussion included "operation cooperation," a project of local cooperation; a plan of operation to conduct a clinic to train judges of synchronized swimming; a plan of operation for conducting a clinic to train judges of diving; and small craft safety.

The idea of cooperation is not new. YMCA's, YWCA's boys' clubs, municipalities, and other groups operating pools have long offered their facilitates for use by other groups and for community learn-to-swim programs. School and college facilities also are often utilized for communitywide activities. However, the CNCA has helped to cement this spirit of cooperation into active programs that should help the efforts of all groups to be more effective.

The need for water safety education exists in every community. Many persons who may not have an opportunity to participate in aquatics in their own community spend some time each year at beaches, pools, lakes, or streams where they are exposed to possible hazards. A steadily increasing number of persons are using small craft, especially in areas where large lakes have been created as a result of power and other projects. In fact it is estimated that nearly 100 million Americans use swimming or small craft facilities each year.
It would be virtually impossible to estimate the exact number of persons who have learned to swim, or who have learned lifesaving through the years. But it is certainly safe to say that well over 15 million persons have been trained in some aspect of swimming and lifesaving and that millions more have been reached with some information and instruction on water safety.

Every group has in its files countless incidents of the effectiveness of this training-of persons young and old who have saved lives because they knew how to make a rescue, how to give artificial respiration, and how to give some kind of assistance to someone in trouble. Less dramatic, but equally important, are the thousands of accidents that never happened because people knew how to swim and knew the basic principles of safety in the water.

Despite the fact that the rate has been cut in half, drowning is still a major cause of accidental deaths. More than 6,000 persons die as a result of drowning each year-about half in swimming accidents and about half in other types, including a large percentage involving small craft. Among persons 5 to 34 years of age, drowning ranks as the second leading cause of accidental death.

Obviously, there is still much to be done. While formal teaching programs may not always be possible because of lack of facilities, much can be accomplished through widespread public education. Many organizations already carry on effective programs using demonstrations, posters, pamphlets, movies, and various publicity media.

With the help of all those who are interested in the health and safety of Americans, the dream of Commodore Longfellow may yet be reached: "Every American a swimmer; every swimmer a lifesaver."

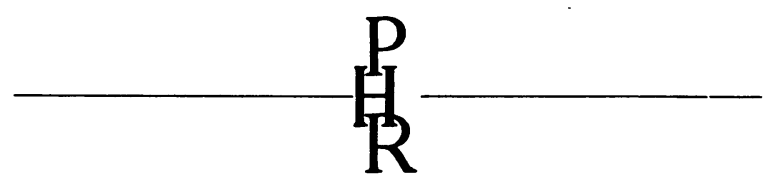

